\title{
EN LOS ENTRESIJOS DE UNA LISTA DE COMEDIAS DE CALDERÓN*
}

ERIK COENEN

Universidad Complutense de Madrid

Menos de un año había transcurrido desde la muerte de Calderón, el 25 de mayo de 1681, cuando Juan de Vera Tassis ya tenía listo para su publicación el primero de los nueve tomos de comedias suyas que llegaría a editar, obteniendo la aprobación y la licencia debidas en abril de 1682. Era la Verdadera quinta parte (1682), así intitulada para distinguirla de una Quinta parte publicada en 1677 y desautorizada por el propio Calderón ${ }^{1}$. Siguieron al mismo elevado ritmo las partes Sexta (1683), Séptima (1683) y Octava (1684), y luego reediciones —enmendadas y retocadas - de las «partes» publicadas y autorizadas en vida del autor: Primera (1685), Segunda (1686), Tercera (1687) y Cuarta (1688). Se anunciaron dos tomos más, pero sólo llegó a salir la Novena parte (1691). En fin, un ritmo de trabajo nada despreciable, sobre todo en los primeros tomos. Sin embargo, ya en aquel primer año después de la muerte del poeta, a Vera Tassis no le faltó tiempo para redactar lo que consideraba una lista exhaustiva de las comedias escritas por Calderón y otra de las que se le atribuían falsamente. En los preliminares de la Verdadera quinta parte, hizo imprimir sus títulos a dos columnas: a la izquierda, los de las «Comedias verdaderas de Don Pedro» (125 títulos, incluidos seis de comedias escritas en colaboración) y a la derecha, los de las «Comedias supuestas, que andan debajo de su nombre» (106 títulos). Volvió a imprimir estas listas en los tomos posteriores, aunque con modificaciones y omitiendo la lista de comedias

\footnotetext{
* Salvo donde se indique una fuente alternativa, los datos bibliográficos recogidos en este artículo están tomados de ediciones originales del siglo XVII consultadas en la Biblioteca Nacional de Madrid, de los catálogos de dicha institución, o, en su defecto, de Kurt y Roswitha Reichenberger, Bibliographisches Handbuch der Calderón-Forschung, I, Kassel, Thiele \& Schwarz, 1979. Sólo se remite a ediciones modernas si contienen información bibliográfica suplementaria relevante. Modernizo la ortografía en la trascripción de citas y títulos, salvo cuando hay motivos para no hacerlo. Por otra parte, después de haber sido aceptado este artículo para su publicación, he conocido un trabajo de Germán Vega García-Luengos, «Consideraciones sobre la configuración del legado de comedias de Calderón» (Criticón, CIII/CIV, 2008, págs. 249-71), coincidente con este en algunos planteamientos.

${ }^{1}$ En el prólogo a la edición de sus Autos sacramentales, de ese mismo año de 1677.
} 
apócrifas a partir de la Primera parte. En su versión final, la lista de comedias auténticas atribuye a Calderón 122 comedias y jornadas individuales de otras ocho.

Ambas listas son las más extensas de su índole que nos han llegado del siglo XVII, y merece la pena examinarlas más detenidamente, no sólo para calibrar la fiabilidad de las atribuciones, sino sobre todo por lo que pueden enseñarnos sobre los textos que tenía a su disposición Vera Tassis: cuestión nada baladí, teniendo en cuenta que publicó 108 comedias de Calderón en versiones cuyo grado de autoridad es a veces muy difícil de determinar. Mi propósito es, sobre todo, indagar cómo fueron compuestas las dos listas.

Sobre el modo de composición de las listas y su fiabilidad ya se pronunció el propio Vera Tassis rotundamente en sus «Advertencias» a los lectores de la Verdadera quinta parte:

Algunas [comedias] más podrá ser se hallen de las que le prohijan, porque hay quien asegure que casi todas cuantas se imprimen en Sevilla para pasar a las Indias las gradúan con el nombre de Don Pedro, por intereses particulares que se les siguen a los que hacen cambio de los talentos ajenos; pero de las legítimas no creo que habrá otra, por tener en mi poder sólo las que he señalado, rubricadas de su mano.

Según esto, en 1682, Vera Tassis estaba muy convencido de tener en su poder todas las comedias auténticas de Calderón, e insinuaba incluso tenerlas todas «rubricadas de su mano». Parece referirse a manuscritos firmados por el autor, lo cual resulta imposible de aceptar, ya que los estudios de la transmisión textual de muchas comedias individuales sugieren que Vera trabajaba a menudo sobre textos impresos. Aun así, no deja de ser llamativa la seguridad en sí mismo que expresan sus palabras en lo que concierne a las comedias «legítimas», frente al elemento de duda que introduce al referirse a «las que le prohijan».

Además del inventario redactado por Vera Tassis, el Siglo XVII nos ha legado dos listas más de las comedias de Calderón. Una es la que fue redactada o completada por Calderón a petición del Duque de Veragua. Abarca seis títulos menos que la primera lista de Vera Tassis y diez menos que la última, en la que influyó, como demostraré más adelante. La tercera lista, que fue presentada a Carlos II por don Francisco de Marañón, nos ha llegado únicamente a través de una copia del Siglo XVIII. Consta de cuatro títulos menos que la lista del Duque de Veragua $^{2}$, siendo comunes con ésta todos los incluidos. De modo que, en su lista de comedias auténticas, Vera Tassis incluye diez títulos que no figuran en las listas de sus contemporáneos. Llegó a publicar siete de ellas, que son todas, a mi juicio, auténticas ${ }^{3}$.

\footnotetext{
2 Vid. Edward M. Wilson, «An early list of Calderón's comedias», Modern Philology, LX, 1962, págs. 95-102.

3 Vid. Erik Coenen, «Las atribuciones de Vera Tassis», Castilla, 0, 2009 (en prensa).
} 
Así pues, la de Vera no sólo es la lista más extensa de su índole redactada en tiempos de Calderón, sino también la más completa. Esto ya de por sí es motivo suficiente para someterla a escrutinio minucioso. Para ello, partiré de la primera redacción — la de la Verdadera Quinta parte de 1682_, con alguna excursión a sus modificaciones posteriores.

\section{LA LISTA DE «COMEDIAS VERDADERAS»}

Como ya señalé, las dos listas van distribuidas en sendas columnas, con las «comedias verdaderas» a la izquierda y las «comedias supuestas, que andan debajo de su nombre» a la derecha, lo cual puede ser reflejo de una redacción simultánea. Cada lista va subdividida en apartados que representan categorías de ediciones. Son cinco en el lado de las «verdaderas»:

1. Las comedias publicadas «en sus tomos»

2. Las publicadas «en los tomos de Varias»

3. Las «manuscritas»

4. «Las que andan impresas sueltas»

5. Las «donde tiene una jornada» Calderón

De muchas comedias de Calderón disponemos de textos antiguos en diversos formatos: en ediciones sueltas, en manuscritos, o adocenados en «Partes»; por lo que, a primera vista, sorprende el hecho de que, para Vera Tassis, cada comedia de Calderón entrara en sólo una de estas cinco categorías y no en varias a la vez. Parece haber aplicado el siguiente principio jerárquico: las comedias que figuran en uno de «sus tomos» (primera categoría), no vuelven a ser nombradas en los apartados siguientes; los títulos de comedias que figuran en «los tomos de varias» (segunda categoría), no vuelven a ser nombrados en los apartados siguientes, etcétera. No está claro si los manuscritos preceden jerárquicamente a las sueltas o viceversa, y de hecho, en este sentido, esta lista no guarda el mismo orden que la de las «supuestas», donde las sueltas —más numerosas - van antes que los manuscritos.

«Comedias verdaderas» publicadas «en sus tomos»

La primera categoría de la lista de comedias auténticas hace referencia a las cuatro Partes publicadas en vida del autor con autorización suya: la Primera parte (1636), la Segunda parte (1637), la Tercera parte (1664) y la Cuarta parte (1672). Excluye la Quinta parte espuria de 1677. Agrega, en cambio, la pro- 
pia Verdadera quinta parte, que Vera a fin de cuentas consideraba la continuación de la serie empezada por las cuatro partes anteriores. Del mismo modo, en cada nueva Parte que publicó, transportaba de los otros apartados a éste los doce títulos de las comedias incluidas en el tomo.

A partir de su reedición de la Primera parte, dejó de incluir la lista de comedias espurias, a la vez que distribuyó ya todos los títulos de las comedias que consideraba auténticas por sus diez respectivas Partes. La lista se convirtió así en un índice de los tomos de comedias de Calderón, incluyendo ya la parte novena — todavía por salir en aquel momento- y la décima, que no llegaría a salir nunca. Fuera de algunas pequeñas modificaciones de los títulos, este índice total se mantiene hasta la Novena parte, en la que - por motivos que se expondrán más adelante - dos de las comedias anunciadas para ese mismo tomo son sustituidas por Un castigo en tres venganzas y Bien vengas, mal. En consecuencia, dos títulos pasan al índice de aquella Décima parte que nunca llegó a ver la luz: San Francisco de Borja y El carro del cielo. Esta última pasa a llamarse El carro del cielo, San Elias, lo cual hace pensar que Vera ya había examinado su texto (que hoy se considera perdido).

«Comedias verdaderas» en «los tomos de varias»

De mayor interés aquí es la segunda categoría, que hace referencia a los libros que reunían comedias de varios autores, principalmente los que conocemos como la serie o colección de Diferentes y su sucesora, la de Escogidas ${ }^{4}$. A diferencia de las comedias de la primera categoría, para las que Vera indica con un número en qué «Parte» fueron publicadas, los títulos apuntados aquí no van acompañados de indicación alguna sobre su procedencia exacta. Sin embargo, es posible descubrir un principio organizador, que se ve muy claramente si reproducimos la lista acompañando cada título con el del «tomo de varias» en el que fue publicada la comedia en cuestión (no modernizo la ortografía, y numero los títulos):

1. No siempre lo peor es cierto

2. La Exaltacion de la Cruz.

3. Mejor està, que estaua

4. Luis Perez el Gallego
Escogidas $1(1652)^{5}$

Escogidas 1

Escogidas 1

Escogidas 1

\footnotetext{
4 Vid. Maria Grazia Profeti, La collezione «Diferentes autores», Kassel, Reichenberger, 1988, y Emilio Cotarelo, Catálogo descriptivo de la gran colección de «Comedias escogidas», Madrid, Tip. de Archivos, 1932.

5 Primera parte de Comedias escogidas de los meiores ingenios de España, Madrid, Domingo García y Morrás, 1652.
} 
5. Con quien vengo vengo ${ }^{6}$

6. Nadie fie su secreto

7. La Vanda, y la Flor ${ }^{8}$

8. Para vencer a Amor, querer vēcerle

9. Darlo todo, y no dar nada

10. Amado, y Aborrecido

11. De agua mansa

12. Las manos blancas no ofenden

13. El Escondido, y la tapada

14. Fuego de Dios en el querer bien

15. Los tres afectos de amor

16. El Ioseph de las Mugeres

17. Las tres Iusticias en vna

18. Cada uno para si

19. Dar tiempo al tiempo

20. Antes que todo es mi Dama

21. No ay cosa como callar

22. Dicha, y desdicha del nombre

23. Zelos aun del ayre matan ${ }^{17}$
Escogidas 1

Escogidas $2(1652)^{7}$

Escogidas $6(1654)^{9}$

Escogidas $7(1654)^{10}$

Escogidas 8 (1657) ${ }^{11}$

Escogidas 8

Escogidas 8

Escogidas 9 (1657) ${ }^{12}$

Escogidas 9

Escogidas 13 (1660) ${ }^{13}$

Escogidas 13

Escogidas 13

Escogidas $15(1661)^{14}$

Escogidas 15

Escogidas $17(1662)^{15}$

Escogidas 17

Escogidas 17

Escogidas 18 (1662) $^{16}$

Escogidas $19(1662)^{18}$

6 Ya se publicó un texto de esta comedia en 1638 en un volumen la serie de Diferentes (Parte treynta vna, de las meiores comedias que hasta oy an salido), pero la lógica interna de la lista de Vera Tassis indica que se refiere al primer volumen de Escogidas.

7 Segunda parte de Comedias escogidas de las mejores de España, Madrid, Imprenta Real, 1652.

${ }^{8}$ La banda y la flor se volvería a publicar con el título de Hacer del amor agravio en la parte 30 (1668).

9 Sexta parte de comedias nuevas escogidas de los mejores ingenios, Zaragoza, Herederos de Pedro Lanaja, 1654. No parece haberse conservado ninguna impresión castellana auténtica de este tomo, si es que existió alguna vez (vid. Maria Grazia Profeti, «Un enigma bibliográfico: la Parte VI de Comedias Nuevas Escogidas», Padova, Università degli studi di Padova: Facultà di Economia e Commercio, 1976).

10 Teatro poético en doze comedias nuevas, de los mejores ingenios de España. Séptima parte, Madrid, Domingo García y Morrás, 1654.

11 Comedias nuevas escogidas de los mejores ingenios de España. Octava parte, Madrid, Andrés García de la Iglesia, 1657.

12 Parte Nona de Comedias escogidas de los mejores ingenios de España, Madrid, Gregorio Rodríguez, 1657.

13 De los mejores el mejor, libro nuevo de comedias varias nunca impresas, compuestas por los mejores Ingenios de España. Parte trece, Madrid, Mateo Fernández, 1660.

14 Parte quinze. Comedias nuevas, escogidas de los mejores ingenios de España, Madrid, Melchor Sánchez, 1661.

15 Parte diez y siete de Comedias nuevas, y escogidas de los mejores ingenios de Europa, Madrid, Melchor Sánchez, 1662.

16 Parte diez y ocho de comedias nuevas, escogidas de los mejores ingenios de España, Madrid, Gregorio Rodríguez, 1662.

17 También publicada posteriormente en la parte 41 (1675).

18 Parte diez y nueve de Comedias nuevas, y escogidas de los mejores ingenios de España, Madrid, Pablo de Val, 1663. 
24. El Maxico Prodigioso

25. Auristela, y Lisidante

26. Andromeda, y Perseo

27. El Secreto a vozes

28. El Pintor de su deshonra

29. La desdicha de la voz.

30. El Alcalde de Zalamea

31. Mañana serà otro dia

32. El Alcayde de si mismo

33. Los Empeños de vn acaso

34. Las Armas de la Hermosura

35. La Señora, y la Criada

36. Fieras afemina Amor

37. La Estatua de Prometeo

38. Amar despues de la muerte
Escogidas $20(1663)^{19}$

Escogidas 20

Escogidas $21(1663)^{20}$

Diferentes $42(1650)^{21}$

Diferentes 42

Diferentes $43(1650)^{22}$

Mejor de los mejores

$(1651 / 1653)^{23}$

Mejor de los mejores

Mejor de los mejores

Mejor de los mejores

Escogidas 46 (1679) ${ }^{24}$

Escogidas 46

Quinta parte $(1677)^{25}$

Quinta parte

Quinta parte

Sobre todo basándonos en los 33 títulos primeros, parece claro que la lista ha sido confeccionada siguiendo un procedimiento ordenado: consultando uno a uno los tomos de Escogidas y anotando los títulos de comedias auténticas de Calderón, y a continuación, haciendo lo mismo con los tomos de Diferentes, sin preocuparse por el hecho de que, cronológicamente, los de Diferentes son anteriores a los de Escogidas. La reaparición de la serie Escogidas en las posiciones 34 y 35 puede parecer extraño, pero admite una explicación lógica. La Parte 46 de Escogidas no sólo es posterior en 16 años a la última parte anterior de la colección que atribuía a Calderón una de las comedias incluidas, sino que es también un libro que sin duda ocupaba un lugar especial en la mente y acaso en la biblioteca de Vera Tassis, ya que incluía tres comedias suyas propias, así

19 Parte veinte de Comedias varias nunca impresas, compuestas por los mejores ingenios de España, Madrid, Imprenta Real, 1663.

20 Parte veinte y una de Comedias nuevas, escogidas de los mejores ingenios de España, Madrid, Joseph Fernández de Buendía, 1663.

21 Parte Quarenta y dos de comedias de diferentes autores, Zaragoza, Juan de Ybar, 1650.

22 Parte Quarenta y tres de Comedias de diferentes autores, Zaragoza, Juan de Ybar, 1650.

${ }^{23}$ El mejor de los mejores libros que han salido de comedias nuevas, Alcalá de Henares, María de Fernández, 1651; y Madrid, María de Quiñones, 1653.

${ }^{24}$ Primavera numerosa de muchas armonias lucientes, en doce comedias fragantes. Parte quarenta y seis. Impresas fielmente de los borradores de los mas celebres plausibles ingenios de España.

25 Es el ya mencionado volumen espurio: Quinta parte de comedias de D. Pedro Calderon de la Barca, Barcelona, Antonio la Cavallería, 1677, y Madrid, Antonio Francisco de Zafra, 1677. La primera no fue realmente impresa en Barcelona por el citado impresor; vid. Jaime Moll, «Sobre la edición atribuida a Barcelona de la Quinta parte de Comedias de Calderón», separata del BRAE, LIII, cuaderno 198, 1973; y Don W. Cruickshank, «The two editions of Calderón's Quinta parte», The Comedias of Calderón, I, ed. de Don W. Cruickshank y John E. Varey, London, Támesis, 1973, págs. 201-210. 
como - tal vez más importante en este contexto- dos comedias de Calderón que el propio Vera había pasado por la imprenta. Ello podría explicar la colocación de estas dos comedias — Las armas de la hermosura y La señora y la criada - fuera del lugar que parece corresponderles. Finalmente, los últimos tres títulos del apartado pertenecen a comedias que se publicaron en la desautorizada Quinta parte de 1677, y es a ese libro que debe de referirse aquí Vera Tassis. Acaso hubiera justificado su inclusión en la categoría de los «tomos de varias» aduciendo que son espurias algunas de las comedias impresas en ella; de todos modos, se trata de un libro que difícilmente tendría cabida en ninguna otra categoría, ya que no lo reconocía como uno de «sus tomos».

La razón por la que Vera sólo menciona tres comedias de la Quinta parte es que las otras siete ya aparecen en otros lugares de sus listas: Darlo todo y no dar nada y Amado y aborrecido figuran ya más arriba en el mismo apartado, por haber sido publicadas, antes que en la Quinta parte, en el tomo octavo de Escogidas (de hecho, es de allí de donde los responsables de la Quinta parte las piratearon); El jardín de Falerina y No hay burlas con el amor (intitulada La crítica del amor en la Quinta parte) las publicaba Vera en la propia Verdadera quinta parte, por lo que incluyó sus títulos en el apartado anterior; y las otras tres —El Rey Don Pedro en Madrid, Cómo se comunican dos estrellas contrarias, y Un castigo en tres venganzas - las consideraba espurias en aquel momento, por lo que las colocó en la lista de «Comedias supuestas», que examinaré más adelante.

Parece ser, pues, que este apartado de la lista fue redactado consultando uno a uno los tomos de Escogidas; luego los de Diferentes y el Mejor de los mejores libros de comedias; a continuación aquel tomo 46 de Escogidas que Vera Tassis conocía demasiado bien para tener que consultarlo; y finalmente, la Quinta parte desautorizada. Hasta aquí, todo parece claro; pero quedan dos problemas importantes que resolver. El más fundamental, cuya solución parcial tendrá que esperar hasta más adelante, se refiere a los criterios aplicados por Vera: ¿cómo decidía cuáles de las comedias atribuidas a Calderón eran realmente suyas, y cuáles no? El otro problema es que los títulos que proporciona Vera no coinciden siempre con los que constan en los tomos de los que parece copiarlos. Es un hecho llamativo, que habrá que examinar más detenidamente. Se trata de los siguientes casos:

Vera Tassis

No siempre lo peor es cierto

Nadie fie su secreto

De agua mansa
Tomos de «Varias»

Nunca lo peor es cierto ${ }^{26}$

No guardas tu tu secreto

Agua mansa

${ }^{26}$ Así en el título y el encabezamiento de las páginas. El índice da el título correcto, No siempre lo peor es cierto. 
El alcalde de Zalamea

Los empeños de un acaso

El alcaide de si mismo

Amar despues de la muerte
El garrote mas bien dado

Los empeños que se ofrecen

La guarda de si mismo

El Tuzani de la Alpujarra

¿En qué se basaba para modificar los títulos? Por supuesto, Vera no ignoraba la costumbre de aludir al título en los versos finales de las comedias; pero aun suponiendo que ello le hizo tomar la molestia de examinar el final de todas las comedias de sus listas, sólo se explicaría así satisfactoriamente la sustitución de Nunca lo peor es cierto por No siempre lo peor es cierto. Podríamos añadir los casos de No guardas tú tu secreto / Nadie fie su secreto y La guarda de sí mismo / El alcaide de sí mismo, pero en estas comedias la alusión al título no es fácil de hallar, ya que no figura en los versos finales sino un poco antes en la escena final ${ }^{27}$. En cambio, tanto en el texto intitulado El Tuzaní de la Alpujarra en la Quinta parte espuria, como en el intitulado Agua mansa en $\mathrm{El}$ mejor de los mejores libros de comedias, los versos finales dan un título ligeramente distinto del que proporciona Vera Tassis: la primera da «amor después de la muerte», con sustantivo (amor) en vez de «amar después de la muerte», con verbo (amar); y la segunda da «del agua mansa» en vez de «de agua mansa» ${ }^{28}$. El alcalde de Zalamea no contiene claras alusiones al título, y aunque Vera sin duda sabía que deriva de una del mismo título atribuido a Lope - ya que la acabaría editando con el título de El alcalde de Zalamea la nueva, obviamente para distinguirla de la «vieja»— debe de haber tenido motivos más sólidos para rechazar el título proporcionado por el libro al que remite su lista. Los versos finales de Los empeños que se ofrecen, tal como figuran en El mejor de los mejores libros de comedias, confirman incluso el título rechazado por Vera Tassis («acaban / los empeños que se ofrecen, / perdonad sus muchas faltas»), y sólo en las jornadas primera y segunda se encuentran alusiones al título correcto, Los empeños de un acaso.

Es cierto que, en el caso de comedias de cierto renombre, no habrá hecho falta tener pruebas documentales para conocer el título correcto. Aún así, en su conjunto, los casos mencionados sugieren que, al redactar sus listas en $1681 \mathrm{o}$ 1682, Vera disponía de textos alternativos de al menos algunas de las comedias

27 En el texto de El alcaide de sí mismo tal como lo publicó Vera Tassis, los versos finales rezan «aqui la Comedia acaba / del Alcayde de si mismo, / perdonad sus muchas faltas»; pero esta alusión al título no figura en el texto del «tomo de varias», que termina más bruscamente en «esta comedia se acaba». Vera pudo haber cogido el título correcto de una suelta temprana (BN T/15038), de la que parece derivar el testimonio intitulado La guarda de si mismo; pero el cotejo con su edición me hace sospechar que no la conocía. Tampoco parece haber conocido el manuscrito de 1669 que conserva la Biblioteca Nacional (Ms/16813), que deriva asimismo de la suelta.

${ }^{28}$ El texto que acabó publicando Vera de esta comedia en su Octava parte, lleva otro título aún, Guárdate del agua mansa, pero los versos finales hablan de «la moraleja / de agua mansa», de acuerdo con el título que figura en la lista. 
cuyos títulos modificó. Ello estaría de acuerdo con lo que sabemos de sus ediciones. Está demostrado que el texto que publicó de Guárdate del agua mansa no deriva del que figura en $E l$ mejor de los mejores libros de comedias ${ }^{29}$. Resulta al menos dudoso que su texto de Amar después de la muerte esté basado en el que en la Quinta parte se intitula El Tuzaní de la Alpujarra ${ }^{30}$. He podido comprobar que la primera jornada de Los empeños de un acaso (Vera Tassis) abunda en variantes textuales y es 85 versos más larga que la de Los empeños que se ofrecen («tomo de varias»), sin que se trate de parches de cosecha propia para remediar pasajes manifiestamente corruptos. En suma, parece lícito concluir que Vera basó algunas de sus modificaciones de los títulos en textos alternativos - manuscritos, sin duda- que tenía en su poder.

Sería raro que Vera sólo poseyera textos alternativos de aquellas comedias que en la versión impresa llevan un título que consideraba erróneo. En efecto, estudios textuales de diversas comedias incluidas en este apartado - Las manos blancas no ofenden, Cada uno para sí, Antes que todo es mi dama, Darlo todo y no dar nada- demuestran o sugieren que Vera trabajó sobre otro texto que el impreso en los «tomos de varias» ${ }^{31}$. He encontrado innegables indicios de lo mismo en Amado y aborrecido y Para vencer amor, querer vencerle ${ }^{32}$. Asimismo, cabe suponer que tenía manuscritos de las dos comedias que había pasado por la imprenta unos años antes en una edición cuyo frontispicio afirmaba precisamente que las comedias incluidas estaban «impresas fielmente de los borradores». Por otro lado, sabemos que Vera manejó la Quinta parte espuria para al menos dos comedias, y que también para su edición de Las tres justicias en una y de La desdicha de la voz dependió, directa o indirectamente, del «tomo de varias» ${ }^{33}$. Es decir, no tenía textos alternativos de todas las comedias de este apartado.

Lo que está claro es que, si bien este apartado puede ser leído como un in-

${ }^{29}$ El agua mansa. Guárdate del agua mansa, Ignacio Arellano y Víctor García Ruiz, eds., Kassel, Reichenberger, 1989, págs. 53-79.

${ }^{30}$ Amar después de la muerte, Erik Coenen ed., Madrid, Cátedra, 2008, págs. 47-59.

${ }^{31}$ Las manos blancas no ofenden, Ángel Martínez Blasco, ed., Kassel, Reichenberger, 1995, págs. 125-128; Cada uno para sí, José María Ruano de la Haza, ed., Kassel, Reichenberger, 1982, págs. 3-93; Antes que todo es mi dama, Bernard P. E. Bentley, ed., pág. 111; Erik Coenen, «Sobre el texto de Darlo todo y no dar nada y la transmisión textual de las comedias de Calderón», Criticón, CII, 2008, págs. 203-209.

32 Vid. Erik Coenen, «Un enigma textual: Amado y aborrecido», Anuario Calderoniano, III, 2010, en prensa.

${ }^{33}$ Edward M. Wilson, «La edición príncipe de Fieras afemina amor de don Pedro Calderón de la Barca», Revista de la Biblioteca, Archivo y Museo, XXIV, 1961, págs. 7-28; La estatua de Prometeo, Margaret Rich Greer, ed., Kassel, Reichenberger, 1986, págs 188-216; Isaac Benabu, On the Boards and in the Press: Calderón's "Las tres justicias en una», Kassel, Reichenberger, 1991, págs. 86-97; para La desdicha de la voz, cfr. las variantes de «C» en la edición de A. V. Ebersole (Chapel Hill, University of North Carolina, 1970). 
ventario de textos que Vera tenía a su disposición para las comedias incluidas, dista mucho de ser exhaustivo como tal. Debe de haber tenido cierta facilidad para hacerse con versiones manuscritas (lo cual no quiere decir necesariamente textos más fiables que los impresos), probablemente gracias a buenos cauces de comunicación con las compañías de actores, que es donde más manuscritos circulaban.

\section{Las «verdaderas» «manuscritas»}

Por su índole de textos sueltos, no parece factible discernir un orden interno en el apartado de los manuscritos, ni en el que le sigue, de las sueltas. El primero, que se refiere probablemente a manuscritos preparados y aprobados para representaciones concretas, abarca dieciocho títulos. Uno de ellos - Los Macabeos- sólo aparece en la lista de la Verdadera Quinta parte y ya no en los tomos posteriores, sin duda porque Vera se dio cuenta de que el manuscrito contenía realmente la comedia Judas Macabeo, publicada ya en 1637 en la Segunda parte. El texto debe haber procedido de una rama temprana de la transmisión textual, ya que Los Macabeos parece ser el título original de la come$\mathrm{dia}^{34}$, pero Vera no parece haberle prestado mucha atención al reeditar, en 1686, la Segunda parte, ya que el texto que ofrece su edición de la comedia reproduce las lagunas de la versión impresa ${ }^{35}$.

Sólo llegó a editar cinco de las comedias de este apartado: Primero soy yo, El segundo Scipión, El castillo de Lindabridis, Céfalo y Pocris y Duelos de amor y lealtad. Con la excepción de Primero soy yo, todas figuran en su edición como «Fiesta que se representó» a Sus Majestades, lo cual constituye un indicio importante de la procedencia de estos manuscritos. De las cinco que llegó a publicar, sólo El segundo Scipión parece haber existido en una versión impresa anterior, y difícilmente la pudo conocer Vera al elaborar sus listas, ya que se trata de una edición suelta impresa en Nápoles en 1681, más o menos al mismo tiempo ${ }^{36}$.

Casi todas las demás comedias de este apartado — anunciadas para esa Décima parte que no llegó a ver la luz - se han perdido, pero tenemos algún testimonio posterior de la existencia de sueltas de Nuestra Señora de los Reme-

\footnotetext{
${ }^{34}$ Hay constancia de una representación con ese título en 1623 (vid. N. Shergold y D. Varey, art. cit., págs. 279-80), y hay un manuscrito temprano en la Biblioteca Nacional (Ms/16558) con el mismo título.

${ }^{35}$ Vid. Fernando Rodríguez-Gallego, «Las dos versiones de Judas Macabeo», Actas del XVI Congreso de la AIH (París, 2007), en prensa.

${ }^{36} \mathrm{El}$ cotejo demuestra, además, que la suelta no es el texto que usó para su edición (incluida en la Séptima parte), sino que esta deriva de la transmisión manuscrita.
} 
dios, San Francisco de Borja, El sacrificio de Efigenia y las dos partes de Nuestra Señora de la Almudena ${ }^{37}$. Puede tratarse de impresiones posteriores a la lista de Vera, pero aunque no sea así, ello no significa necesariamente que se equivocara, sino que en su jerarquía clasificatoria los manuscritos preceden a las sueltas.

Se conservan manuscritos de El segundo Scipión (dos, fechados en 1676 y 1678) y de El acaso y el error, así como de la primera jornada de Primero soy yo (1644), pero de ninguna comedia más de las recogidas como «manuscritas». Aparte de las publicadas por Vera y El acaso y el error, todas pueden considerarse perdidas. Ocho de estas figuran también en la lista del Duque de Veragua (El carro del cielo, La Celestina, El triunfo de la cruz, Don Quijote de la Mancha, Certamen de amor y celos, San Francisco de Borja, y las dos partes de Nuestra Señora de la Almudena), lo cual parece confirmación suficiente de que existieron en algún momento y de que Calderón fue su autor ${ }^{38}$. Si aceptamos la atribución de Nuestra señora de los Remedios a Calderón por Fajardo ${ }^{39}$, cabe concluir que, de las comedias incluidas en este apartado, La Virgen de Madrid es la única de la que no tenemos más prueba que la palabra de Vera Tassis para suponer que existió y que fue escrita por Calderón.

Más problemáticos resultan en este sentido los dos títulos añadidos a partir de la Sexta parte, ninguno de los cuales figura en la lista del Duque de Veragua. Uno es Desagravios de María, comedia de la que no se han conservado ni textos ni referencias documentales ${ }^{40}$. El otro es El condenado de amor, título que lleva una comedia muy mediocre conservada en un manuscrito del siglo XVIII ${ }^{41}$; cabe preguntarse si es realmente la comedia a la que alude Vera.

\footnotetext{
${ }^{37}$ Juan Isidro Fajardo, Títulos de todas las comedias que en verso español o portugués se han impreso hasta el año de 1716 (Biblioteca Nacional, Ms/14706), fols. 38v y 46v.

38 El triunfo de la cruz ha sido identificada con La exaltación de la cruz, puesto que este título no figura en las listas de Veragua y de Marañón, y aquél sí. Tal hipótesis supondría, en primer lugar, que el propio autor se equivocó dos veces en el título que había puesto a su comedia - que era La exaltación de la cruz según el penúltimo verso y según todos los textos conservados-; y en segundo lugar, que Vera Tassis se equivocó al creer que eran dos comedias diferentes; lo cual es mucho suponer.

39 También en Francisco Medel del Castillo, Índice general alfabético de todos los títulos de comedias, Madrid, Alfonso de Mora, 1735.

${ }^{40} \mathrm{El}$ documento aportado por Hartzenbusch (en el cuarto volumen de su edición de las comedias de Calderón en la BAE, Madrid, Atlas, 1945, pág. 675) para dar constancia de su representación en 1640 parece demostrar más bien que la obra representada fue el auto sacramental $\mathrm{La}$ hidalga del valle.

${ }^{41}$ Se encuentra en la Biblioteca Nacional de Madrid, con la signatura Ms/15097. La comedia sobrevive también en otro manuscrito (Ms/16039), fechado en 1750, con el título de También la Deydad es Juez y Amor castiga Perjuros y unas pocas, pero llamativas, variantes textuales; da como autor a un tal Francisco de Alcántara Pabial, del que no he podido hallar más rastro.
} 


\section{Las «sueltas verdaderas»}

La categoría de las comedias auténticas impresas sueltas abarca sólo tres títulos: La cisma de Inglaterra, Las cadenas del Demonio y Los cabellos de Absalón. Parece que Vera tenía razón en que sólo circulaban en dicho formato, ya que de ninguna de las tres existe un texto anterior a su edición que no sea una suelta. De La cisma de Inglaterra no ha sobrevivido ni eso; y el que Vera consiguiera su texto es un indicio más de la facilidad que debe de haber tenido para encontrar textos, ya que se trata de una comedia temprana, representada en $1627^{42}$. La autoría de Calderón de La cisma de Inglaterra y de Los cabellos de Absalón es indiscutible. La de Las cadenas del demonio, en cambio, ha sido puesta en entredicho ${ }^{43}$, pero no alcanzo a entender por qué.

\section{«Donde tiene una jornada»}

La última categoría que distingue Vera Tassis, y que sólo aplica a las «verdaderas», es la de las comedias «donde [Calderón] tiene una jornada». Nótese que este criterio no refiere, como los otros, al formato en que se publicaron (partes, tomos de varias, manuscritos, sueltas), sino al hecho de haber sido escritas en colaboración. Las atribuciones parecen ser correctas, pero el catálogo que da Vera, y que abarca sólo seis títulos en 1682, no es exhaustivo. Faltan, por ejemplo, La más hidalga hermosura ${ }^{44}$ y El jardín de Falerina, comedias ambas cuya jornada tercera es Calderón. Faltan también aquellas comedias de las que Calderón escribió la mitad (que no «una jornada», estrictamente hablando), como Troya abrasada (con Zabaleta) o Yerros de Naturaleza y aciertos de la Fortuna (con Coello), que sólo han sobrevivido en manuscrito. Los títulos que da Vera Tassis en la Verdadera Quinta parte son:

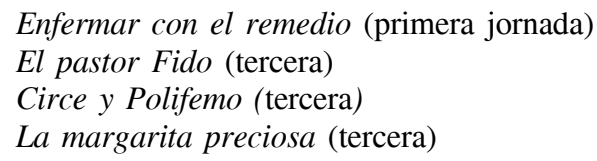

Escogidas $4^{45}$

Escogidas 8

¿Suelta?

Escogidas 21

${ }^{42}$ N. D. Shergold y J. E. Varey, «Some early Calderón dates», Bulletin of Hispanic Studies, XXXVIII, 1961, p. 277.

${ }^{43}$ Vid. Wilson, art. cit., pág. 103. También en Don W. Cruickshank \& Edward M. Wilson, op. cit., p. 141. Para una demostración de la autoría de Calderón, vid. Erik Coenen, «Las atribuciones...», art. cit.

${ }^{44}$ Vera pudo ver esta comedia en la Parte 43 de Diferentes, de la que registró La desdicha de la voz; pero figura en dicho tomo como «de tres ingenios».

${ }^{45}$ Laurel de Comedias. Quarta Parte de Diferentes Autores, Madrid, Imprenta Real, 1653. 
El monstruo de la fortuna (primera) ${ }^{46}$

El mejor amigo, el muerto (tercera)
Escogidas $24^{47}$

Escogidas 9

También aquí se percibe un orden global que sigue los tomos de Comedias nuevas escogidas, pero con dos irregularidades: la colocación de El mejor amigo, el muerto al final, en vez de su lugar correspondiente después de El pastor Fido; y la inserción en el tercer puesto de una comedia, Circe y Polifemo, que no me consta se publicara en ningún «tomo de varias». De esta comedia se conserva un manuscrito (signatura Res/83) en la Biblioteca Nacional, cuya tercera jornada es, en efecto, de Calderón (autógrafa además), pero cuyo título es, según los versos finales, Polifemo y Circe, al revés de como lo da Vera Tassis. La jornada tercera - la única que lleva un título en el manuscrito- va como El Polifemo, que es como se llama la comedia en los otros textos que se conservan. Sin embargo, tenemos otros testimonios del título proporcionado por Vera, Circe y Polifemo, en los catálogos de Fajardo y de $\mathrm{Medel}^{48}$, por lo que cabe suponer que se refiere a una suelta con tal título.

Reviste cierto interés el que, a partir de la Sexta parte, figure en este apartado también una jornada de El privilegio de las mujeres. Se conocen tres testimonios tempranos de esta comedia, ninguno de los cuales da como autor (parcial) a Calderón. Dos son sueltas, y una de estas debe ser la princeps y lleva lo que parece ser el título correcto, Los privilegios de las mujeres. Vera casi seguramente la conocía de la Parte treinta de Diferentes, donde figura como enteramente de Montalbán ${ }^{49}$. Parece haber tenido sus propios motivos para atribuir una de las jornadas a Calderón, como se deduce del hecho de que, después de adjudicarle inicialmente la jornada primera, cambió de parecer para atribuirle la tercera (a partir de la Segunda parte). Recuérdese que unos años antes, Vera había pasado por la imprenta Las armas de la hermosura, comedia en la que Calderón recicló partes de — precisamente_ las jornadas primera y tercera de El privilegio de las mujeres. Hay que precisar que su reutilización de la jornada primera se limita a pequeños trozos de dos romances, mientras de la tercera copió casi palabra por palabra una silva entera. Sin duda, la atribución inicial de la primera jornada a Calderón y el posterior cambio de parecer de Vera guarda relación con estos hechos.

46 Vera Tassis añade: «en la parte 24», lo cual indica que tenía también presente la Séptima parte de Escogidas, en la que figura una comedia de Lope de Vega con el mismo título. El dato constituye una prueba más de lo bien que dominaba Vera Tassis la materia.

${ }^{47}$ Parte veinte y quatro de Comedias nuevas, y escogidas de los mejores ingenios de España, Madrid, Mateo Fernández de Espinosa Arteaga, 1666.

${ }^{48}$ Fajardo (fol. 13r.) atribuye erróneamente la jornada primera a Montalbán y la segunda a Mira de Amescua en vez de a la inversa. En otro lugar da el título Polifemo y Circe (fol. 41v).

49 En los catálogos y manuales al uso consta que figura como de Calderón, Montalbán y Coello, error originado en De la Barrera. 
El caso de El privilegio de las mujeres es también de interés por otra razón. La Parte treinta de Diferentes es la misma que incluye el famoso texto «Z» —la «primera versión»- de La vida es sueño, por lo que parece lícito deducir que Vera conocía esta versión de la comedia más célebre de Calderón y que pudo aprovechar algunas de sus variantes al editarla, como ya sospechaba Sloman ${ }^{50}$.

En la Octava parte se modifica de nuevo este apartado, añadiéndose la tercera jornada de La fingida Arcadia. En todos los testimonios hoy conservados -incluyendo dos anteriores a la lista de Vera Tassis: en Escogidas XXV (1666) y en la Segunda parte de las comedias de don Agustín Moreto (1676) — esta comedia figura como enteramente de Moreto. No sé en qué se basaba Vera para asociar la tercera jornada a Calderón; pero me inclino a darle la razón. Dicha jornada reviste ciertos rasgos estilísticos suyos, y consta en ella un neologismo («parante», como antónimo burlesco de «(caballero) andante») que Calderón emplea también en Cada uno para sí, Basta callar y El escondido y la tapada ${ }^{51}$.

\section{LA LISTA DE «COMEDIAS SUPUESTAS QUE ANDAN DEBAJO DE SU NOMBRE»}

Esta lista abarca no cinco sino tres categorías. Falta, como es natural, la de las comedias recogidas «en su partes», pues obviamente son todas auténticas. Falta también la de las comedias «donde tiene una jornada». La primera categoría de esta lista es, por lo tanto, la de las comedias que figuran en el «juego de varias» (como lo llama Vera Tassis aquí).

Sugerí antes que las dos listas pueden haber sido redactadas simultáneamente, es decir, que Vera repasaba los «tomos de varias», y después los textos manuscritos y las ediciones sueltas, anotando a la izquierda las que daba por auténticas y a la derecha las que no. El análisis de esta lista corroborará esta suposición, y proporcionará indicios de cómo separaba el grano de la paja.

Recordemos primero que la Cuarta parte de comedias de Calderón incluye un prólogo del propio autor con una lista de 41 títulos de comedias que, según él, no eran suyas. Vera da nada menos que 106 títulos (y nueve más a partir de la Sexta parte), por lo que no se puede haber basado únicamente en la lista proporcionada por Calderón; pero un examen atento de sus listas sugiere que la de Calderón influyó de modo importante en su decisión de otorgar un título a una u otra, especialmente en cuanto a los que iba encontrando en los «tomos de varias».

${ }^{50}$ En la introducción a su edición de la comedia, Manchester, University Press, 1961, pág. xxxvi.

${ }^{51}$ Marcella Trambaioli se inclina también, sin entrar en consideraciones estilísticas y léxicas, a atribuir a Calderón la jornada tercera de La fingida Arcadia («La fingida Arcadia de 1666. Autoría y escritura de consumo», Moretiana. Adversa y próspera fortuna de Agustín Moreto, ed. de María-Luisa Lobato y Juan Antonio Martínez Berbel, Frankfurt am Main /Madrid, Vervuert / Iberoamericana, 2008, págs. 185-208). 
«Comedias supuestas» en «el juego de varias»

Como era de prever, este apartado sigue, como el apartado correspondiente de la lista paralela, el orden de los tomos de Escogidas, aunque con algunas irregularidades y entradas sorprendentes. Lo reproduzco, siguiendo las mismas pautas que para el apartado gemelo, numerando los títulos y señalando los volúmenes en los que aparecen atribuidos a Calderón; un asterisco indica que el mismo título fue recogido por Calderón en su lista de la Cuarta parte:

1. *Los Empeños de seis horas

2. *La Tercera de si misma

3. *El Escandalo de Grecia

4. *La Española de Florencia

5. *El Vencimiento de Turno

6. *Los Desdichados dichosos

7. *Las Canas en el papel

8. *El Conde Lucanor

9. El mejor Padre de Pobres (=*San Juan de Dios)

10. *Los Empeños de vn plumage

11. *Amor, ingenio, y muger

12. *Seneca, y Neron

13. *El Rigor de las desdichas

14. *Saber desmentir sospechas

15. *Las Visperas Sicilianas

16. Industria contra el poder

17. *Vencerse es mayor valor

18. *Mudanças de la fortuna (= * El rigor en las desdichas)

19. Los zelos hazen Estrellas

20. El Tuzani de las Alpujarras

21. El Rey Don Pedro en Madrid

22. Como se comunican dos Estrellas contrarias

23. Vn castigo en tres venganças

24. Sucesos del Principe Lisardo

25. Marco Antonio, y Cleopatra

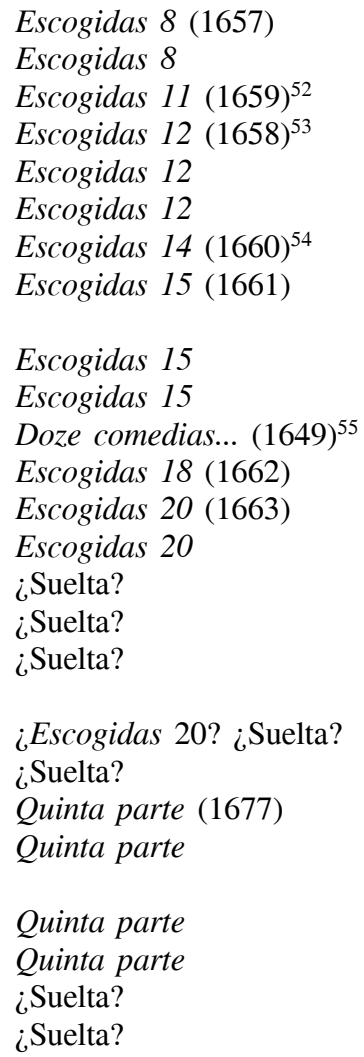

\footnotetext{
52 Comedias nuevas escogidas de los mejores ingenios de España. Onzena Parte, Madrid, Gregorio Rodríguez, 1659.

${ }^{53}$ Comedias nuevas escogidas de los mejores ingenios de España. Duodécima Parte, Madrid, Andrés García de la Iglesia, 1658.

${ }^{54}$ Pensil de Apolo, en doze Comedias nuevas de los mejores ingenios de España. Parte catorze, Madrid, Domingo García y Morrás, 1660.

${ }_{55}$ Doze comedias las más famosas que asta aora han salido de los meiores y mas insignes poetas, tercera parte, Lisboa, Antonio Álvarez, 1649.
} 
Como se ve, de los primeros dieciocho títulos, dieciséis figuran también en la lista de Calderón; y podemos añadir uno más, El mejor padre de pobres, que es un título alternativo de la comedia San Juan de Dios, también incluida por Calderón en su lista. La única excepción es, pues, La industria contra el poder, que en realidad es una comedia auténtica, ya que con este título fue publicada Amor, honor y poder en la Parte 28 de Diferentes (Zaragoza, 1633), pero con atribución a Lope de Vega. Por esta misma razón, difícilmente puede referirse Vera Tassis a ese volumen, de modo que no se sabe de ningún «tomo de varias» en el que pudo haber visto La industria contra el poder con atribución a Calderón. Sólo conocemos hoy sueltas con tal atribución.

Vera incluye aquí todas las comedias que van atribuidas a Calderón en los «tomos de varias» y que no recoge entre las «verdaderas» ${ }^{56}$. Hay que constatar, sin embargo, que no se limitó a copiar la lista de Calderón, ya que el orden de los primeros catorce títulos no sigue ésta, sino el de las Partes sucesivas de Escogidas. La única excepción es Amor, ingenio y mujer, que no parece ocupar el lugar que le corresponde. Está incluida en el tomo 32 de Diferentes, pero con atribución a Mira de Amescua, por lo que Vera no puede referirse a esa edición. Debe de haber visto el texto en un libro intitulado Doze comedias las más famosas que asta aora han salido de los meiores y mas insignes poetas, tercera parte (Lisboa, Antonio Álvarez, 1649), en el que sí figura adjudicada a Calderón, pero ello no explica como su título pudo colarse entre los de Escogidas, si no es por alguna causa trivial o fortuita.

Vencerse es mayor valor figura como de Calderón en el interior de la oncena Parte de Escogidas, pero ya en el índice se señala que es «de los Figueroas [en referencia a Diego y José Figueroa y Córdoba], que aunque está dentro de Don Pedro Calderón se erró al escribirlo». De ese volumen deben derivar las ediciones sueltas que atribuyen la obra a Calderón sin más. Mudanzas de la fortuna es la segunda parte del título completo de El rigor en la desdicha, con el que figura tanto en Escogidas como en alguna edición suelta: El rigor en la desdicha y mudanzas de la fortuna (incluida con ambos títulos parciales en la lista de Calderón). No está claro si su inclusión aquí remite a Escogidas —como

\footnotetext{
${ }^{56}$ Emilio Cotarelo (op. cit., pág. 46, seguido por Reichenberger, op. cit., I, págs. 46 y 813) afirma que la comedia Travesuras son valor va atribuida a Calderón en la Octava parte de Escogidas. Según esto, sería la única excepción, puesto que Vera no menciona este título; pero en realidad, el que se equivocó fue Cotarelo, ya que la comedia va anónima en dicho libro. Cabe mencionar también el caso, en cierto sentido similar, de tres comedias auténticas de Calderón publicadas en Diferentes y Escogidas con un título diferente: La devoción de la cruz (en la Parte 28 de Diferentes, 1634, como La cruz en la sepultura), La banda y la flor (en la Parte 30 de Escogidas, 1668, como Hacer del amor agravio) y De una causa dos efectos (en la Parte 37 de 1671 como El amor hace discretos): la primera figura como de Lope de Vega, y las otras dos como de «un ingenio de esta corte», por lo que ni el título ni la autoría daban motivo a Vera para fijarse en ellas al elaborar su lista.
} 
supone esta categoría - o a una suelta. No figura tampoco en ningún «tomo de varias» hoy conocido Las vísperas sicilianas (pero sí a una suelta, con el título completo de Los agravios satisfechos y vísperas sicilianas), y lo mismo puede decirse de Los celos hacen estrellas, Sucesos del Príncipe Lisardo (Sucesos del Príncipe Lisardo y donair6es de Mengo), y Marco Antonio y Cleopatra. De ésta última se ha recuperado una edición suelta que lleva el nombre de Calderón ${ }^{57}$, y si bien las conservadas de Sucesos del príncipe Lisardo y Los celos hacen estrellas van anónimas o con otra autoría, de ambas deben de haber existido sueltas atribuidas a Calderón, ya que de ellas dan constancia tanto Fajardo en 1713 como Medel del Castillo en 1735.

De modo que figuran en este apartado, antes y después de los títulos de la Quinta parte espuria, varias entradas que hoy sólo podemos identificar, directa o indirectamente, como sueltas. Se ha postulado alguna vez la existencia y posterior pérdida de siete tomos de la serie de Diferentes ${ }^{58}$, y sería una hipótesis necesaria para justificar la inclusión de estas entradas en este apartado; pero no deja de ser sumamente inverosímil que esos volúmenes hipotéticos no hayan dejado rastro alguno, ni siquiera en los catálogos del siglo XVIII.

Quedan por considerar los cuatro títulos que proceden de la espuria Quinta parte. Conviene recordar aquí que Calderón, en el prólogo a la edición de sus Autos sacramentales de 1677, negó su autoría de ese mismo número -cuatro- de las diez comedias incluidas en la denostada Quinta parte. Las palabras del poeta («de diez comedias que incluye, no ser las cuatro mías») siguen causando perplejidad hoy ${ }^{59}$, y es razonable suponer que también Vera Tassis, convencido de que había que incluir cuatro en la lista de las «supuestas», se preguntara a cuáles se refería. Sospecho que aplicó un principio eliminativo: tres comedias de la Quinta parte figuran ya como de Calderón en los «tomos de varias» anteriores (Amado y aborrecido, Darlo todo y no dar nada y No hay burlas con el amor), otras tres aparecen en la Quinta parte como «fiesta que se hizo a sus majestades» - y Vera estaba muy al tanto de tales representaciones, de las que consiguió no pocos textos, y en las que difícilmente cabía fingir autorías falsas-, por lo que las apócrifas tenían que ser las cuatro restantes: Un castigo en tres venganzas, El Rey don Pedro en Madrid, Cómo se comunican dos Estrellas contrarias y El Tuzaní de las Alpujarras.

\footnotetext{
${ }^{57}$ Germán Vega García-Luengos, «Treinta comedias desconocidas de Ruiz de Alarcón, Mira de Amescua, Vélez de Guevara, Rojas Zorrilla y otros de los mejores ingenios de España», Criticón, LXII, 1994, pág. 63. No es la única suelta de las mencionadas aquí cuya recuperación se debe al profesor Vega.

58 Maria Grazia Profeti, op. cit., pág. 8.

59 Tradicionalmente, se han considerado apócrifas sólo dos de las comedias incluidas: El Rey Don Pedro en Madrid y Cómo se comunican dos estrellas; y con toda probabilidad es también auténtica ésta última. Vid. Germán Vega García-Luengos, «Imitar, emular, renovar en la «comedia nueva»: Cómo se comunican dos estrellas contrarias, reescritura calderoniana de Las almenas de Toro», Anuario Lope de Vega, XI, 2005, págs 243-264.
} 
El problema era que, como ya hemos indicado, este último lo consideraba sólo un título erróneo de una comedia auténtica, Amar después de la muerte. Sin embargo, la inclusión de una comedia auténtica entre las supuestas tiene un antecedente en el propio Calderón, que incluyó su comedia El Conde Lucanor en su lista de ajenas, justificándose en lo mutilado del texto impreso en Escogidas. Nótese que, con respecto a El Conde Lucanor, Vera siguió a Calderón en la octava entrada de este apartado; según se desprende de sus «Advertencias» al lector, mete el Tuzaní en el mismo saco:

De la comedia del Conde Lucanor, que pongo por suya y por ajena, hallará el escrupuloso en el Cuarto Tomo de sus Comedias entera satisfacción; y de la de Amar después de la muerte, la daré a su tiempo.

Se nota en estas declaraciones que le incomodaba hasta al propio Vera la inclusión de El Tuzaní de la Alpujarra / Amar después de la muerte aquí. A fin de cuentas, en la Quinta parte «falsa» había otra comedia con el título cambiado —No hay burlas con el amor, publicada como La crítica del amor-, que Vera publicaba en la propia Quinta parte «verdadera», sin incluirla entre las apócrifas con el título erróneo, lo cual no dejaba de ser inconsecuente. Se le complicó más aún el asunto unos años más tarde, cuando tuvo que transferir Un castigo en tres venganzas a la lista de comedias auténticas, lo cual le obligó a su vez a meter también esta obra en el mismo saco que El Conde Lucanor; es decir, considerarla una obra rechazada por Calderón por el grado de corrupción textual:

La Comedia de Amar después de la muerte (como dejé advertido en la Verdadera quinta parte) la desconoció por suya Don Pedro, no tanto por hallarla con el título del Tuzaní de la Alpujarra, cuanto por verla adulterada y diminuta en la impresión. La de Un castigo en tres venganzas, que también está en la Quinta falsa, padecía la misma calamidad. («Al lector», Novena parte)

Detrás de todo esto se vislumbra un intento de acomodar en sus listas aquella enigmática declaración de Calderón sobre las «cuatro» comedias ajenas halladas en la Quinta parte de 1677.

No quiero pasar por alto aquí el curioso detalle de la trascripción exacta del título «falso» de Amar después de la muerte. Estudios de la transmisión textual de diversas comedias demuestran que Vera manejaba siempre la primera edición de la Quinta parte, la supuestamente impresa en Barcelona ${ }^{60}$. Ésta carece

\footnotetext{
${ }^{60}$ Vid. Cecilia Bainton y Don Cruickshank en su estudio preliminar de Fieras afemina amor, Edward Wilson, ed., Kassel, Reichenberger, 1984, pág. 13; Margaret Rich Greer en su estudio textual de La estatua de Prometeo, ed. cit., pág. 215; y Don Cruickshank y Seán Page en la introducción a su traducción inglesa de No hay burlas con el amor (Love is no laughing matter, Warminster, Aris \& Philips, 1994, pág. xxix).
} 
de índice, pero en el interior del libro la comedia se llama El Tuzani del Alpuxarra, tanto en el título como en el encabezamiento de las páginas. Aunque se llama igual en la segunda edición (impresa en Madrid por Antonio de Zafra), en el índice pasa a intitularse El Tuzani de las Alpujarras, en plural y con jota, exactamente como transcribe el título Vera Tassis quince años más tarde. ¿Poseía, entonces, ambas ediciones de tan denostado libro?

En suma, no está libre de incógnitas este apartado. No obstante, si optamos por ignorar las siete entradas enigmáticas, resulta posible reconstruir el procedimiento seguido por Vera, sobre todo teniendo en cuenta la innegable evidencia que encontraremos en el siguiente apartado de que iba consultando la lista de Calderón publicada en su Cuarta parte. Primero, Vera repasaba simplemente los índices de los «tomos de varias», y cada vez que encontraba un título atribuido a Calderón, lo apuntaba a la derecha si lo veía rechazado en dicha lista, y a la izquierda en caso contrario (corrigiendo sobre la marcha algún título). Luego, añadió los cuatro títulos de la Quinta parte espuria que, según sus propias conjeturas, debían ser los cuatro denunciados por Calderón en el prólogo a sus Autos sacramentales.

Lo que no parece cuadrar con tal hipótesis son aquellos siete títulos que no figuran atribuidos a Calderón en ningún «tomo de varias» hoy conocido, sino sólo en sueltas. Acaso las vio Vera en algún efímero volumen colecticio que identificó como un «tomo de varias».

\section{Comedias supuestas sueltas}

La categoría de las sueltas constituye un vasto problema bibliográfico. No cabe duda de que se han perdido muchas, por lo que es imposible saber a qué ejemplares concretos podría estarse refiriendo Vera Tassis. Además, el elevado número que recoge en la categoría de «supuestas» — nada menos que 73 títulos falsamente atribuidos a Calderón - no es fácil de manejar. Aun así, algo se puede descubrir sobre la manera en que fue elaborado este apartado.

$\mathrm{Al}$ redactarlo, Vera sigue consultando la lista de la Cuarta parte, pero omitiendo los títulos ya incluidos en el apartado anterior. Una vez establecido que fue éste su método de trabajo, su aplicación es fácil de percibir, sobre todo en los primeros títulos. Pongo a la izquierda los primeros 23 títulos de la lista de Calderón, y a la derecha los primeros 16 de Vera Tassis; indico como «[tomos de varias]» aquellos que Vera omite por haberlos recogido en el apartado anterior:

1. Los Triunfos de Ioseph

2. La Paciencia de Iob

3. Las Visperas Sicilianas

4. La Batalla de Sopetran
1. Los Triunfos de Ioseph

2. La Paciencia de Iob [tomos de varias]

3. La Batalla de Sopetràn 
5. La Roca del Honor

6. La Codicia Rompe el Saco

7. La Palabra en la Muger

8. Mudanças de la Fortuna

9. Seneca y Neron

10. Saber Desmentir Sospechas

11. San Iuan de Dios.

12. La Victoria de Fuente-Rabia

13. Del Rey Abaxo Ninguno

14. El Escandalo de Grecia

15. El Casamentero

16. La Respuesta està en la Mano

17. Amor con Amor se Obliga

18. El Rigor de las Desdichas

19. Del mal pagador en Pajas

20. El Mayor Rey de los Reyes

21. El Rollo de Ezija

22. El Texedor de Segouia

\section{El Conde Don Sancho Niño}

4. La Roca del honor

5. La codicia rompe el saco

6. La Palabra en la muger

[tomos de varias]

[tomos de varias]

[tomos de varias]

[tomos de varias: El mejor padre de pobres]

7. La Victoria de Fuente-Rabia

8. Del Rey abaxo, ninguno

[tomos de varias]

9. El Casamentero

10. La respuesta està en la mano

11. Amor con amor se obliga

[tomos de varias]

12. El mal pagador en pajas

13. El Mayor Rey de los Reyes

14. El Rollo de Ecija

15. El Texedor de Segouia, primera y segunda parte

16. El Conde Don Sancho Niño

Al redactar el apartado anterior, Vera seguía el orden de los «tomos de varias» con un ojo puesto en la lista de Calderón. En este apartado, sigue el orden de la lista de Calderón, como es evidente. Sin embargo, hay que notar que no lo hace mecánicamente. Ya vimos que, al redactar el apartado anterior, se había dado cuenta de que la San Juan de Dios, en la lista de Calderón, es la misma comedia que El mejor padre de pobres, tal como se intitula en Escogidas XV, por lo que lo incluyó allí y lo omite aquí. Se aparta también de la lista de Calderón al precisar que El Texedor de Segouia tiene una «primera y segunda parte»; efectivamente, es una comedia en dos partes, y de ambas existen sueltas atribuidas a Calderón. Como veremos, unas líneas más abajo corrige un título que da Calderón, El imposible fácil, como El imposible más fácil, que es, en efecto, como se intitula realmente esta comedia de Matos Fragoso. Todo lo cual indica que Vera no se limitó a copiar la lista de Calderón, sino que la tuvo delante mientras repasaba una cantidad importante de comedias sueltas, buscando las comedias correspondientes a las entradas de Calderón.

A partir del vigésimo cuarto título proporcionado por Calderón, Vera altera ligeramente el orden de los títulos e inserta, además, dos que no están en la lista del propio autor:

\section{El Imposible Facil}

17. La Prudente Abigail

18. El imposible mas facil

19. El castigo del penseque 
25. El Saco de Amberes

26. El Mejor Testigo el Rey

27. El Prodigio de Alemania

28. El Venturoso por Fuerça

29. Enseñar a ser Buen Rey

30. El Esclauo de Maria
20. El Mejor Testigo el Rey

21. El Prodigio de Alemania

22. El Saco de Amberes

23. El Venturoso por Fuerça

24. El Esclauo de Maria

25. Enseñar a ser Buen Rey

No sé por qué aparecen en estas posiciones La Prudente Abigail y El castigo del penseque. La primera es una comedia de Antonio Enríquez Gómez, de la que no se conoce hoy ningún texto en que figure como de Calderón, aunque existe un auto sacramental suyo con el mismo título. La segunda es una comedia de Tirso, y tampoco figura como de Calderón en ninguna edición conservada. Sin embargo, ambas comedias son atribuidas a Calderón por Medel del Castillo, y Fajardo atestigua la existencia de una sueltas de La prudente Abigail.

Calderón prosigue su lista con Los Empeños que se Ofrecen, título que no recoge Vera Tassis, sin duda por darse cuenta de que era la misma comedia que Los empeños de un acaso, que con razón consideraba auténtica ${ }^{61}$. Acaso Calderón se había dejado engañar por el título alterado, ya que es difícil ver qué razones pudo tener para querer disimular su autoría de esta obra.

De los diez títulos restantes de la lista de Calderón, ocho son recogidos por Vera en el apartado anterior; con que sólo quedan dos por mencionar aquí: $E l$ Perdon Castiga Mas, que ocupa, en efecto, el lugar siguiente en la lista de Vera Tassis; y Haz Bien, y Guardate, que figura, sorprendentemente, 24 posiciones más abajo.

Pasemos ahora a considerar brevemente las decenas de títulos de otras sueltas «supuestas» que Vera añadió al catálogo publicado por Calderón, rechazando su autoría frente a las tres sueltas que sí aceptó como suyas. Son muchas las que se conservan en efecto con atribución a Calderón ${ }^{62}$. De otras no ha sobrevivido texto alguno, pero podemos inferir que existieron con tal atribución, ya

${ }^{61}$ Los empeños de un acaso figura igualmente como de Calderón en las listas de Veragua y de Marañón, pero existen dos sueltas que la atribuyen a Montalbán. Esta última atribución ha sido defendida por Maria Grazia Profeti («Los empeños de un acaso de Calderón. Los empeños que se ofrecen de Juan Pérez de Montalbán», Actas del «Congreso internacional sobre Calderón y el teatro español del Siglo de Oro, III, Luciano García Lorenzo, coörd., Madrid, CSIC, 1983, págs. 249-254), pero a mi juicio, el estilo y el enredo no dejan lugar a dudas.

${ }^{62}$ Es el caso de Las mujeres cuando quieren; Engañar para reinar; El lucero de Castilla; El paje de Don Álvaro (que es en realidad la misma comedia que la anterior); Muchos indicios sin culpa; Celos ofenden al sol; Yo me entiendo; La bárbara de los montes; El día de San Blas en Madrid; La dicha del retraído; Honra, confusión y amor; El pedir con mal intento; Huyendo vence el honor; Lo que hace un manto; El Rey ángel; Cada cual a su negocio; El ángel de la guarda; Duelo de honor y amistad; El galán sin dama; Quien calla, otorga; Las amazonas; El Fénix de España; El mejor testigo es Dios, y El mejor testigo, el Rey, que es la misma que El mercader de Toledo. 
que también Medel las da como de Calderón ${ }^{63}$. De otras sólo se conservan sueltas con atribución a otro autor, pero son asimismo adjudicadas a Calderón por Medel ${ }^{64}$. Vicente García de la Huerta parece haber conocido un texto de La cena del Rey Baltasar (comedia, no auto) con atribución a Calderón ${ }^{65}$. Donaires de Mengo es la misma comedia que Los sucesos del Príncipe Lisardo, incluido en el apartado anterior; y El amor hace prodigios debe de ser la misma obra que Los celos hacen estrellas, cuyos versos finales dicen «los celos hacen estrellas / y el amor hace prodigios». Sólo de Obrar bien, que Dios es Dios (comedia de Montalbán); de El blasón de los Mendozas; y de El caballo que vos han muerto (que es la misma comedia que la anterior, conservada con atribución a Luis Vélez de Guevara) no hay constancia de otra atribución a Calderón que la que rechaza Vera Tassis; parece razonable suponer que existieron, que Vera las llegó a ver, y que se han perdido.

Quedan por mencionar cinco comedias parcial o totalmente auténticas, y reconocidas como tal por el propio Vera, que él recoge en este apartado con los títulos que llevan en algunas ediciones sueltas. Uno de estos títulos es La industria contra el poder, que ya había incluido en el apartado anterior y que repite en este; y se puede decir que lo repite una vez más como El honor contra la fuerza, que es parte del título completo que lleva esta misma comedia en algunas sueltas (La industria contra el poder y el honor contra la fuerza, con atribución a Calderón en algunas y a Lope en otras); se trata, como ya establecimos, de Amor, honor y poder. Las tres edades de España es, en realidad, Origen, pérdida y restauración de la Virgen del Sagrario, que lucía ya desde 1637 en la Segunda parte de Calderón. El amor hace discretos es la misma comedia que De una causa dos efectos, que también es auténtica; aparece con el título «falso» y el nombre de Calderón en algunas sueltas tardías ${ }^{66}$. Por último, El Polifemo es un título con el que, con atribución a Calderón, lleva en una suelta tardía Polifemo y Circe, así como en la segunda parte de Doze comedias de las mas grandiosas (Lisboa, P. Craesbeeck, 1647), libro que Vera Tassis no parece haber conocido. No es del todo injustificado considerar falsa la atribución a Calderón, ya que las primeras dos jornadas efectivamente no son de él.

${ }^{63}$ Es el caso de Los encantos del Marqués de Villena; El premio añade el valor; Lo que merece el valor; y El Castañar de Toledo (cuyo título hace sospechar que es, en realidad, Del Rey abajo, ninguno, de autoría incierta pero atribuida a Rojas Zorrilla).

${ }^{64}$ Porfiando vence amor y El casamiento en la muerte son comedias de Lope; Prueba de amor y amistad es de Tirso; Los riesgos que tiene un coche figura en la Parte 4 de Escogidas con atribución a Antonio de Mendoza; de Cada cual lo que le toca se conserva una suelta con atribución a Rojas Zorrilla; y de La mayor fineza sólo se conserva una suelta anónima.

${ }^{65}$ Lo incluye como de Calderón en su Catálogo alfabético de las comedias, tragedias, autos, zarzuelas, entremeses y obras correspondientes al theatro español de 1785. Huerta, como Medel, redactó su catálogo antes de la gran pérdida de textos iniciada en 1808.

${ }^{66}$ Figura también en la Parte 37 de Escogidas, pero atribuida no a Calderón sino a «un ingenio de esta corte». 
Ya en la Sexta parte de 1683, Vera añadió nueve títulos a este apartado. Dos de ellos (A lo que obliga un agravio y Las dos bandoleras) constituyen otro caso más de una sola comedia con dos títulos diferentes; fue escrita por Matos Fragoso y Sebastián de Villaviciosa, pero Medel la atribuyó a Calderón, lo mismo que otros seis de estos títulos ${ }^{67}$. Sólo de El amante mudo no tenemos más indicios de una atribución a Calderón que su inclusión en este apartado. Tal vez lo más interesante de la adición de títulos en la Sexta parte es lo que dice sobre su facilidad para encontrar este tipo de ediciones, confirmando su vaticinio, antes citado, de que podrían encontrarse más ediciones sueltas de las comedias «que le prohijan».

Las repeticiones, y sobre todo la inclusión de comedias auténticas con el título cambiado, obligan a concluir que este apartado fue redactado con poco cuidado. Uno se pregunta si Vera llegó en algún momento a examinar estas sueltas más allá de sus encabezamientos. Da la sensación de que daba por sentado que era apócrifa cualquier comedia suelta publicada con nombre de Calderón que él no conociera como obra auténtica suya. Es decir que, si no me equivoco, aplicaba el principio opuesto al aplicado en el apartado anterior: en los «tomos de varias», cualquier comedia atribuida a Calderón la consideraba auténtica si no había sido tildada de ajena por el propio autor; las comedias publicadas como sueltas, en cambio, las consideraba apócrifas si no tenía buenas razones para creer lo contrario.

Si esto es así, la incógnita fundamental de esta sección no reside en por qué Vera descartó la autoría de Calderón de tantas comedias, sino en por qué eximió de ese juicio negativo las tres sueltas incluidas en el lado de las auténticas: La cisma de Inglaterra, Las cadenas del Demonio y Los cabellos de Absalón. Lo cual reduce el problema a dimensiones mucho más manejables.

Señalemos finalmente que, si este fue el proceder de Vera, resulta probable que se equivocara en algunos casos. Se han encontrado fuertes indicios de que, incluso entre las comedias rechazadas por el propio Calderón, hay algunas - como El prodigio de Alemania, San Juan de Dios, La batalla de Sopetrán y El perdón castiga más - que son parcial o totalmente auténticas ${ }^{68}$, y bien pue-

67 Despreciar lo que se quiere, La mejor luna africana, Aristómenes Mesenio, La fe de Abraham, Las lágrimas de David y Dios hace justicia a todos.

68 Germán Vega García Luengos, «Calderón y la política internacional: las comedias sobre el héroe y traidor Wallenstein», Calderón de la Barca y la España del Barroco, II, J. Alcalá Zamora y E. Belenguer, coords., CEPC-SEENM, Madrid, 2001, págs. 793-827; «Ecos de Rosaura (para leer mejor el inicio de La vida es sueño e incrementar el repertorio calderoniano)», Estaba el jardín en flor... Homenaje a Stefano Arata. Criticón 87-88-89 2003, págs. 887-898; «La leyenda de Sopetrán en una comedia que compromete a Calderón», La hagiografía entre historia y literatura. Homenaje a Henri Guerreiro, Marc Vitse, ed., Universidad de Navarra / Iberoamericana / Vervuert, Pamplona / Madrid / Frankfurt am Main, 2005, págs. 1113-1134; «Las credenciales calderonianas de otra comedia rechazada por Calderón: El perdón castiga más», El Siglo de Oro en escena. Homenaje a Marc Vitse. Criticón, Presses Universitaires du Mirail, Toulouse, 2007, págs. 1053-1069. 
de haber más casos. A este respecto, es llamativo el elevado número de comedias incluidas en este apartado (y algunas en el anterior) que en todos los testimonios conservados van atribuidos a Calderón. Determinar la autoría de estas comedias no será fácil, sobre todo porque todavía conocemos mal el estilo de los epígonos de Calderón, pero no hay que excluir alguna adición futura al canon calderoniano.

\section{Comedias supuestas manuscritas}

Podemos ser más breves sobre la última categoría que distingue Vera Tassis, en la que incluye sólo ocho comedias ajenas. Que yo sepa, la única de la que se conserva un manuscrito es Santa Theodora, si es que se trata del texto anónimo que se conserva en la Biblioteca Nacional (signatura 14955), y que lleva hoy como título Famosa comedia de Santa Teodora por otro nombre pusoseme el sol; según su editor moderno, es de Andrés de Claramonte ${ }^{69}$. No consta ninguna atribución a Calderón de La necedad del discreto, que es de Lope. Parece ser del mismo autor La fianza satisfecha, pero la atribución a Calderón es confirmada en los catálogos de Fajardo y de Medel, lo mismo que la de El Capitán Cornejo, La pulida sayaguesa, La Duquesa Rosimunda y Los Reyes Magos, todas hoy perdidas. La única restante, la también perdida Aventuras de Oliveros y lealtad de Artur de Algarve, es asimismo atribuida a Calderón por Medel. Es decir que hay testimonios de ediciones sueltas atribuidas a Calderón de seis de las ocho comedias de este apartado. Pueden ser de fecha posterior, pero no parece muy probable. Acaso lo que tenía o había visto Vera eran precisamente manuscritos que desmentían tal atribución. Difícil es saberlo, y difícil es saber qué valor dar a su evaluación de la autoría de comedias manuscritas. Mucho tendrá que ver la índole y las circunstancias de cada manuscrito, sobre las que sólo cabe conjeturar.

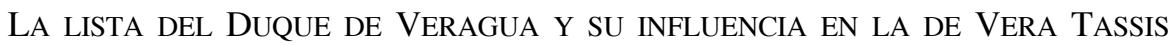

Según sus propias afirmaciones, Vera Tassis sabía distinguir las comedias autenticas de las erróneamente atribuidas por tener aquéllas en su poder, «rubricadas de su mano». El primero en declarar su incredulidad ante tal pretensión fue su contemporáneo Gaspar Agustín de Lara en un prólogo de 1684, innegablemente hostil a Vera Tassis ${ }^{70}$ :

\footnotetext{
${ }^{69}$ Andrés de Claramonte, Púsoseme el sol, saliome la luna, Alfredo Rodríguez López-Vázquez, ed., Kassel, Reichenberger, 1985.

${ }^{70}$ Gaspar Agustín de Lara, Obelisco funebre, pyramide funesto a la inmortal memoria de D. Pedro Calderon de la Barca, Madrid, Eugenio Rodríguez, 1684.
} 
¿Quién podrá haber que se persuada que la memoria de todas las comedias que se ponen en la Verdadera quinta parte, está rubricada de Don Pedro, cuando él mismo confiesa «que las desconocía por el contexto, y por los títulos no?». Porque, ¿cómo había de firmar aquello que desconocía por suyo? Y siendo esto así, tampoco habrá quien crea rubricó los títulos por donde las conocía; pues no pudo Don Pedro prevenir en vida el que después de muerto hubiese quien pretendiese hacer creer al mundo que firmaba por propio lo que confirmaba por ajeno.

La cita de Calderón («que las desconocía por el contexto, y por los títulos no») remite a una carta suya que reproduce Lara al final de su prólogo, escrita en 1679 en respuesta a una del Duque de Veragua pidiéndole, precisamente, una «memoria» completa de sus comedias — que es esa misma prestigiosa lista que hemos mencionado en varios lugares de estas páginas-, y otra con los títulos de sus autos sacramentales. Lara reprodujo ambas listas al final de su prólogo, al parecer con intención de desautorizar la ofrecida por Vera Tassis ${ }^{71}$.

Vera no conocía la «memoria» del Duque de Veragua hasta verla publicada en el Obelisco fúnebre. Lo prueban, a mi juicio, varios detalles de los preliminares de su reedición de la Primera parte (1685), el primer tomo que sacó a la luz después de la publicación del Obelisco fúnebre.

La lista del Duque atribuye a Calderón una comedia temprana - De un castigo tres venganzas - que, como vimos, Vera había dado por espuria con el título de Un castigo en tres venganzas (que es el que lleva en la desautorizada Quinta parte); y le atribuye otra -Bien vengas, mal, si vienes solo- que Vera no había incluido en ninguna de las dos listas. El Duque incluye además, en su lista de los autos sacramentales de Calderón, Los obreros del señor, que al parecer Vera tampoco consideraba auténtico. Pues bien, no puede ser fortuito que, en la citada Parte de 1685, Vera incluya una lista alternativa de los autos sacramentales de Calderón, en respuesta a la del Duque; que Un castigo en tres venganzas pase sin más explicaciones de la lista de las «supuestas» a la de las «verdaderas», pasando además a intitularse De un castigo tres venganzas, como en la lista del Duque; que Vera deje de incluir la lista de «supuestas»; y que denuncie en su prólogo las deficiencias de «otras memorias», a la vez que niegue la autoría de Calderón de Los obreros del señor y Bien vengas, mal:

El [auto] de Los obreros del Señor, que anda en otras memorias por suyo, es de Don Francisco de Rojas, impreso más ha de sesenta años; y ni éste, ni la Comedia Bien vengas mal, si vienes solo había de arrogarse Don Pedro, dejando de poner más de veinte grandes Comedias, y más de veinte y seis mayores Autos.

${ }^{71}$ Este prólogo no figura en todos los ejemplares. De los seis que posee la Biblioteca Nacional de Madrid, el que lleva la signatura el 2/69642 incluye el prólogo pero no las «memorias» de comedias y autos de Calderón que lo acompañan; y el 2/44857 omite tanto el prólogo como las memorias. 
La finalidad de esta frase es, sin duda, desautorizar la lista del Duque («otras memorias»), tal como Lara se había servido de ésta para desautorizar la de Vera. Lo prueban el rechazo de Los obreros del señor y Bien vengas mal, así como la insistencia en las omisiones («más de veinte grandes Comedias, y más de veinte y seis mayores Autos» ${ }^{72}$ ). A la vez, la disimulada intervención con respecto a Un castigo en tres venganzas / De un castigo tres venganzas delata que tomaba en serio la lista del Duque, y que le hizo examinar el texto y cambiar de parecer.

Vera acabó rectificando su error respecto a Bien vengas, mal, publicando la comedia en 1691, en la Novena parte, junto con De un castigo tres venganzas. Ya hemos citado unas frases del prólogo de esta Parte en el contexto de sus empeños de identificar las cuatro comedias de la Quinta parte espuria tildadas de ajenas por Calderón. Es de interés ahora completar la cita y releerla a la luz de la lista del Duque, teniendo en cuenta que en ésta Amar después de la muerte figura con el título rechazado por Vera, El Tuzaní de la Alpujarra:

La Comedia de Amar después de la muerte (como dejé advertido en la Verdadera quinta parte) la desconoció por suya Don Pedro, no tanto por hallarla con el título del Tuzaní de la Alpujarra, cuanto por verla adulterada y diminuta en la impresión. La de Un castigo en tres venganzas, que también está en la Quinta falsa, padecía la misma calamidad; y por eso se anota allí, y aquí se publican ambas, desmintiendo los errores de la Prensa. La de Bien vengas mal dije en el Primer Tomo que no era de Don Pedro, a causa de haber visto otra con el mismo título; y registrando esta que ahora presento, reconozco, por lo artificioso de la traza y la naturaleza del verso, que es legítimo parto suyo.

Está clara la relación con la lista del Duque de Veragua, tanto por la alusión al título alternativo de Amar después de la muerte como por las menciones de Un castigo en tres venganzas y Bien vengas, mal. Las explicaciones que ofrece Vera son poco convincentes, sobre todo la que refiere a esa «otra con el mismo título», que debe ser un mero pretexto para exculparse de su error.

Esto no significa necesariamente que ignorase la existencia de Bien vengas mal en 1682 y que se hubiese hecho con su texto en el ínterin. Hoy no se conserva ningún texto completo de la comedia que no derive de la edición de Vera, pero el catálogo de Fajardo da constancia de una edición suelta que iba atribuida a «un ingenio». Es posible que fuera ésta la edición que vio Vera; que

\footnotetext{
${ }^{72}$ En realidad la lista del Duque incluye sólo ocho comedias menos — no «más de veinte»— que la más reciente publicada por Vera en aquel momento (o dieciséis, si se incluyen las ocho «donde tiene una jornada»). La cifra de veintiséis autos se ajusta un más a la verdad, ya que la en lista del Duque figuran 70 títulos —uno de ellos espurio, según Vera-, mientras en la publicada por éste hay 95 (aunque uno de ellos, El laberinto del mundo, figura dos veces, y se repiten varios autos con títulos alternativos).
} 
su anonimia le hiciera inicialmente descartar sin más la autoría de Calderón; que la publicación de la lista del Duque le impulsara a examinarla más detenidamente; y que acabara aceptando — «por lo artificioso de la traza y la naturaleza del verso»- que era de Calderón. También puede ser que consiguiera el texto manuscrito de una representación palaciega de la comedia, como sugiere el encabezamiento que lleva en su edición, «Fiesta que se representó a sus Majestades en el Salón Real de Palacio». En cuanto a De un castigo tres venganzas, todo indica que seguía dependiendo de la Quinta parte, ya que en su edición la comedia vuelve a intitularse Un castigo en tres venganzas, igual que en su lista inicial ${ }^{73}$.

\section{¿«RUBRICADAS DE SU MANO»?}

Está claro que Vera Tassis, en 1682, no disponía de versiones manuscritas firmadas por el autor ni de Bien vengas mal ni de De un castigo tres venganzas, ni de otras muchas comedias de Calderón. Por otro lado, como vimos, está comprobado que tenía textos alternativos de no pocas comedias, lo cual atestigua cierta facilidad para encontrarlos. También para una o más de las comedias incluidas en la propia Verdadera quinta parte (Hado y divisa de Leonido y Marfisa, tal vez Los dos amantes del cielo) trabajó sobre un manuscrito. Debe haber tenido manuscritos de algunas de las comedias clasificadas como tal en su lista: seguramente de las cinco que llegó a editar, aunque persiste la incógnita sobre las otras, casi todas perdidas. Es sabido que incluso para sus reediciones de las cuatro Partes publicadas en vida del autor, recurrió a buenos textos alternativos de al menos dos comedias: El mayor monstruo del mundo (o El mayor monstruo, los celos) y El laurel de Apolo.

«Rubricados de su mano» o no, lo más probable es que los manuscritos que manejó procedían de las propias compañías de teatro. Señalamos antes que cuatro de las cinco comedias que llegó a publicar en la categoría de las manuscritas, figuran como «Fiesta que se representó» a Sus Majestades en una ocasión concreta. Es de notar que otras muchas comedias que en su edición llevan un encabezamiento semejante, no lo llevan en las versiones impresas a las que remite su lista. Ello sugiere que los textos en cuestión le fueron proporcionados por las tropas de actores que representaban en palacio. Lo más habitual era que tales textos derivaran de versiones impresas anteriores, pero precisamente en el caso de representaciones palaciegas resulta plausible que el propio autor intervi-

${ }^{73}$ El título con que figura la comedia en la lista del Duque, De un castigo tres venganzas, es el mismo que lleva en el tomo 28 de Diferentes (1634), libro que Vera debe de haber hojeado al elaborar su lista inicial. No sé si es que se olvidó de este texto o si lo consideraba menos fiable. 
niera en la corrección, revisión y eventual adaptación del texto, lo cual complica aún más el problema de la autoridad de las ediciones de Vera ${ }^{74}$.

Las rúbricas de Calderón sólo pueden haberle ayudado en muy contados casos para determinar la autoría de comedias concretas. Hemos visto fuertes indicios de que, para las comedias impresas, Vera elaboró su lista en base a una combinación de sus propios conocimientos y una serie de conjeturas: que todas las comedias atribuidas a Calderón en los «tomos de varias» eran suyas salvo las que había rechazado explícitamente en la Cuarta parte; que tenía que haber cuatro comedias ajenas en la Quinta parte espuria; y que las comedias que iban atribuidas a Calderón en ediciones sueltas no eran suyas, salvo si había motivos para suponer lo contrario. Vera parece haber sobreestimado su conocimiento de las comedias de la primera época de Calderón (muchas de ellas escritas antes de su nacimiento); de ahí sus errores iniciales con respecto a De un castigo tres venganzas y Bien vengas mal, y de ahí también su desconocimiento de otra comedia auténtica de Calderón, La selva confusa, así como de algunas obras tempranas escritas en colaboración. Parece haber confiado más de lo debido en que todo título que no conociera como de Calderón era de mano ajena, por lo que añadió sin más a la lista de apócrifas títulos como Las tres edades de España, La industria contra el poder y El amor hace discretos, sin darse cuenta de que eran comedias auténticas publicadas con un título diferente (error que, en cambio, no llegó a cometer con Los empeños que se ofrecen). Vistos los hoy crecientes indicios de que Calderón quiso disimular su autoría de algunas comedias tempranas, habrá que decir incluso que se fió demasiado de la lista de comedias ajenas confeccionada por el propio autor. Esto difícilmente podemos echárselo en cara, pero sugiere que todavía queda bastante trabajo por hacer para que podamos establecer un canon lo más completo y definitivo posible de las comedias de Calderón.

\footnotetext{
${ }^{74}$ Vid. Erik Coenen, «Del libro al palacio, del palacio al libro. Una hipótesis sobre la transmisión textual de las comedias de Calderón», Actas del VIII Congreso de la AISO (2008), Santiago de Compostela, en prensa.
} 